\title{
IN-LINE FILTRATION INCREASE PATIENTS' SATISFACTION ON PERIOPERATIVE PERIPHERAL VENOUS CANNULATION: A QUALITATIVE SURVEY.
}

\author{
Dr. Giua R., Dr. Villa G., Dr. Biondi S., Dr. Barbani F., Dr. Balsorano P., Dr. Selmi V., Dr. Zagli G., Dr. Chelazzi C., \\ Dr. Romagnoli S., Dr. Pinelli F.
}

Department of Health Science, Section of Anaesthesia and Intensive Care, University of Florence Azienda Ospedaliera Universitaria Careggi, Florence, Italy

BACKGOUND: Thrombophlebitis is a frequent complication of peripheral venous cannulation (PVC) among hospitalized patient undergoing surgical procedures ${ }^{1}$. It often produces severe discomfort, pain and movement limitation. As previously demonstrated, in-line filtration had an independent effect in reducing postoperative thrombophlebitis in a cohort of surgical patient ${ }^{2}$. The aim of this qualitative survey is to evaluate the effect of in-line filtration in improving satisfaction on perioperative PVC.

METHODS: 268 patients enrolled in the previous trial ${ }^{2}$ were telephone recalled 6 months after their hospital discharge and analysed through a self-reported quativative/qualitative questionnaire. This assessed several domains related to PVC, such as the overall patients' satisfaction, comparison with previous experience, discomfort, functional limitation and chronic symptoms related to post-phlebitis syndrome.

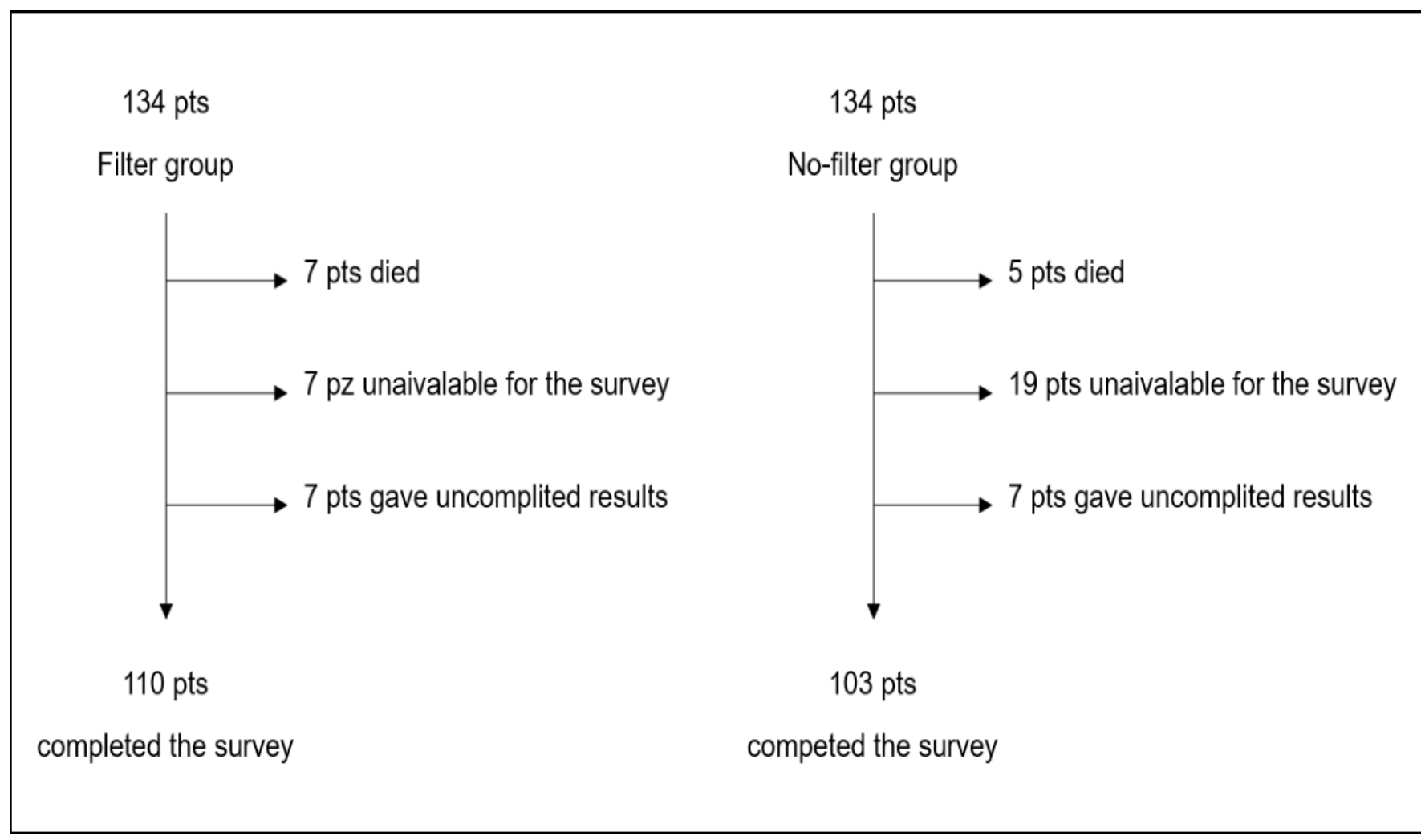

Fig. 1The selection process for the qualitative/quantitative questionnaire.

RESULTS: Among the original population enrolled in the randomized trial, $110(82 \%)$ and $103(76.9 \%)$ patients respectively for in-line filtration and control groups were available for this prospective survey Fig. 1 .

Within in-line filtration group, $97.3 \%$ of patients were satisfied/really-satisfied on the perioperative management of their PVC; if compared with previous experiences on PVC, $11 \%$ of them recognized in-line filtration as a relevant causative factor in determining their satisfaction. Among patients within control group, 93.2\% were satisfied/really-satisfied on the perioperative management of their PVC, although up to $30 \%$ of them experienced postoperative phlebitis. At the qualitative interview they recognized no differences than previous experiences on PVC, and mentioned postoperative phlebitis as a usual complication that "normally occur" during hospital stay. Un-satisfied patients were double in the control group (6.8\%) than in the in-line filtration group (2.7\%). Every un-satisfied patient within in-line filtration group had a venous cannula of large diameter, placed in a site different than the recommended cephalic vein of the arm and presented postoperative phlebitis.

\begin{tabular}{|c|c|c|c|c|c|c|}
\hline & \multicolumn{3}{|c|}{ Filter group ( $n=110)$} & \multicolumn{3}{|c|}{ No-filter group ( $n=103$ ) } \\
\hline & $\begin{array}{l}\text { RS/S patients } \\
n=107(97.3 \%)\end{array}$ & $\begin{array}{c}\mathrm{RU} / \mathrm{U} / \mathrm{N} \\
\text { patients } \\
\mathrm{n}=3(2.7 \%)\end{array}$ & $\mathbf{p}$ & $\begin{array}{l}\text { RS/S patients } \\
n=96(93.2 \%)\end{array}$ & $\begin{array}{c}\mathrm{RU} / \mathrm{U} / \mathrm{N} \\
\text { patients } \\
\mathrm{n}=7(6.8 \%)\end{array}$ & $\mathbf{p}$ \\
\hline Phlebitis incidence & $4(3.7 \%)$ & $3(100 \%)$ & 0.001 & $27(28.1 \%)$ & $3(42.9 \%)$ & 0.41 \\
\hline $\begin{array}{l}\text { Cannula anatomic location } \\
\text { Median cubital vein } \\
\text { Cephalic vein of the forearm } \\
\text { Superficial dorsal veins of the hand }\end{array}$ & $\begin{array}{c}3(2.8 \%) \\
79(73.8 \%) \\
25(23.4 \%)\end{array}$ & $\begin{array}{c}0 \\
0 \\
3(100 \%)\end{array}$ & 0.001 & $\begin{array}{c}3(3.1 \%) \\
69(71.9 \%) \\
24(25.0 \%)\end{array}$ & $\begin{array}{c}0 \\
2(28.6 \%) \\
5(71.4 \%)\end{array}$ & 0.04 \\
\hline Previous PVC & $82(93.2 \%)$ & $2(66.7 \%)$ & 0.21 & $65(67.7 \%)$ & $7(100 \%)$ & 0.10 \\
\hline $\begin{array}{l}\text { Improvement compared to } \\
\text { previous PVC }\end{array}$ & $9(11 \%)$ & 0 & 0.62 & 0 & 0 & - \\
\hline Discomfort in daily activities & $1(0.9 \%)$ & $3(100 \%)$ & 0.001 & $5(5.2 \%)$ & 3 (42.9\%) & 0.01 \\
\hline
\end{tabular}

CONCLUSIONS: In-line filtration contributes, beside other good practices on insertion and management of PVC, in increasing patient satisfaction and reducing PVC-related discomfort. To the best of our knowledge, this is the first study aimed to evaluate the patients' perspective on in-line filtration, both qualitatively and quantitatively. No comparison with previous results is thus available.

1. Niël-Weise BS et al. Should in-line filters be used in peripheral intravenous catheters to prevent infusion-related phlebitis? A systematic review of randomized controlled trials. Anesth Analg. 2010;110(6):1624-1629.

2. Villa G. et al. In-Line Filtration Reduces Postoperative Venous Peripheral Phlebitis Associated With Cannulation: A Randomized Clinical Trial. Anesth Analg. 2018;Apr 23 